\title{
17.6\% Conversion Efficiency Multicrystalline Silicon Solar Cells Using the Reactive Ion Etching with the Damage Removal Etching
}

\author{
Ji-Myung Shim, ${ }^{1}$ Hyun-Woo Lee, ${ }^{1}$ Kyeong-Yeon Cho, ${ }^{1}$ Jae-Keun Seo, ${ }^{1}$ Ji-Soo Kim, ${ }^{1}$ \\ Eun-Joo Lee, ${ }^{1}$ Jun-Young Choi, ${ }^{1}$ Dong-Joon Oh, ${ }^{1}$ Jeong-Eun Shin, ${ }^{1}$ Ji-Sun Kim, ${ }^{1}$ \\ Ji-Hyun Kong, ${ }^{1}$ Soo-Hong Lee, ${ }^{2}$ and Hae-Seok Lee ${ }^{1}$ \\ ${ }^{1}$ R\&D Center, Solar Cell Division, Shinsung Solar Energy, Seongnam-Si, Gyeonggi-do 463-420, Republic of Korea \\ ${ }^{2}$ Department of Electronic Engineering, Sejong University, Seoul 143-747, Republic of Korea \\ Correspondence should be addressed to Ji-Myung Shim, shimjm@shinsung.co.kr
}

Received 31 August 2011; Revised 31 December 2011; Accepted 31 December 2011

Academic Editor: Junsin Yi

Copyright () 2012 Ji-Myung Shim et al. This is an open access article distributed under the Creative Commons Attribution License, which permits unrestricted use, distribution, and reproduction in any medium, provided the original work is properly cited.

For lower reflectance, we applied a maskless plasma texturing technique using reactive ion etching (RIE) on acidic-textured multicrystalline silicon (mc-Si) wafer. RIE texturing had a deep and narrow textured surface and showed excellent low reflectance. Due to plasma-induced damage, unless the RIE-textured surfaces have the proper damage removal etching (DRE), they have a drop in $V_{\text {oc }}$ and FF. RIE texturing with a proper DRE had sufficiently higher short circuit current $\left(I_{\text {sc }}\right)$ than acidic-textured samples without a drop in open circuit voltage $\left(V_{\mathrm{oc}}\right)$. And in order to improve efficiency of mc-Si solar cell, we applied RIE texturing with optimized DRE condition to selective emitter structure. In comparison with the acidic-textured solar cells, RIE-textured solar cells have above $200 \mathrm{~mA}$ absolute gain in Isc. And optimized RIE samples with a DRE by $\mathrm{HNO}_{3} / \mathrm{HF}$ mixture showed $17.6 \%$ conversion efficiency, which were made using an industrial screen printing process with selective emitter structure.

\section{Introduction}

In order to improve the solar cell performance, incoming light in the cell has to be coupled into the cell and transformed into electrical energy more effectively. Losses due to reflection and transmission of the incident light have to be reduced to increase the solar cell efficiency. A texture causes a multiple reflection on its surface. Therefore, the amount of collected light into the substrate, depending on the amount reflections, increases. This increase of collection, together with the larger average path length of the light in the substrate, causes an increased possibility of absorption [1].

Numerous techniques for texturing mc-Si have been examined in the past. Many approaches have been based on isotropic wet acidic etching. This method does not provide the extremely low reflection but does have the advantages of being relatively easy to implement and low cost. Some have focused on the use of RIE, either in conjunction with a mask to achieve large, regular features or without a mask to produce much smaller and more random texture [2]. RIE is a kind of plasma etching, not only the chemical etching of the plasma species, but also the kinetic energy of its ions. From the time plasma etching was applied in the semiconductor industry for patterning Si substrates, it is known that plasma etching, under certain conditions, causes a surface texture of a very high roughness [3]. Reflectivity can be minimized to below $1 \%$ [4]. Decrease in reflectivity does not automatically lead to an improvement of cell efficiency. It is known that a less rough form of this texture can be used for more effective light coupling into Si substrates $[5,6]$. The reflectivity can be well controlled by RIE. This way of texturing is ideal for very fragile substrates. According to previous studies, RIE textured surface has shown extremely low reflectance [7]. However, surface damage may be caused by RIE-texturing [8] and result in a high surface recombination velocity due to the enlarged surface. RIE-textured cells have reduced quantum efficiency in the short wavelength, unless the RIE-textured surface receives the proper DRE [7]. Because problem of RIE may be that the energetic ions can introduce damage in the Si material [9], so Carriers have a large chance of 


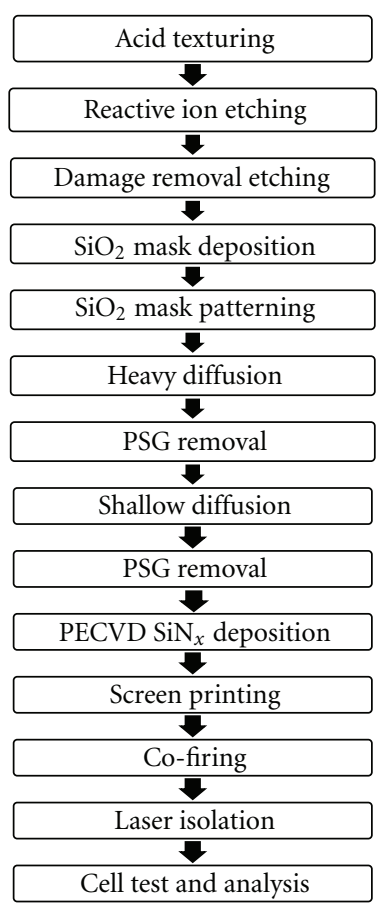

FIGURE 1: Fabrication process for screen-printed selective emitter mc-Si solar cells with RIE texturing.

recombining at the needles of the surface and will not reach the $\mathrm{p}$-n junction. In order to remove this problem, we studied DRE using $\mathrm{HNO}_{3} / \mathrm{HF}$ mixture with various etching time. The aim of this work was to find DRE conditions that create a texture with a low reflectance and without a drop of $V_{\text {oc }}$ and FF, which obtains a maximum improvement for $I_{\mathrm{sc}}$ and conversion efficiency. And for high efficient mc-Si solar cell, we applied selective emitter technique on screen printing process with RIE texturing.

\section{Experiment}

The fabrication process is outlined in Figure 1. In this work, solar grade multi-crystalline silicon wafer of size $156 \times$ $156 \mathrm{~mm}^{2}$, boron doped p-type, was used. And resistivity $1.9 \mathrm{ohm} \cdot \mathrm{cm}$ and thickness $200 \mathrm{um}$ were taken. The isotropic texturing of mc-Si wafer was carried out by using acidic solutions. Then acid-textured Si wafers were processed in an RIE reactor. After RIE texturing, we investigated various DRE times with acidic solution (dilute $\mathrm{HNO}_{3}$ and $\mathrm{HF}$ mixture) to determine which produces the highest cell performance with screen-printed solar cell process. A sequence with diluted $\mathrm{KOH}$ and $\mathrm{HCl} / \mathrm{HNO}_{3}$ treatments has been found not to affect the visual appearance of the texture structure. The textured surface was analyzed using a scanning electron microscope (SEM). $\mathrm{SiO}_{2}$ layer was deposited as diffusion barrier mask. To form the selective emitter structure, mask was patterned by etch paste for heavily diffusion. These wafers was doped in conventional tube furnace using $\mathrm{POCl}_{3}$ liquid source. The phosphorous silicate glass (PSG) and remaining $\mathrm{SiO}_{2}$ was removed with a $10 \% \mathrm{HF}$ solution simultaneously. A shallow diffused region is created by $\mathrm{POCl}_{3}$ diffusion. A shallow diffused region is created by $\mathrm{POCl}_{3}$ dif- fusion. After second diffusion, sheet resistance below the contact fingers were $20 \Omega / \square$ and between fingers were $80 \Omega / \square$, respectively. And PSG was removed with a $10 \% \mathrm{HF}$ solution. The SiNx layer was deposited on the emitter, using direct PECVD. Refractive index and thickness of PECVD SiNx layer were 2.06 and $85 \mathrm{~nm}$, respectively. Next, the Ag and $\mathrm{Al}$ pastes were screen-printed onto the front and back of each sample and cofired in a lamp-heated belt furnace. The cells were isolated using a laser, and the cells were tested using the solar simulator.

\section{Results and Discussion}

To improve cell efficiency, we applied RIE on mc-Si wafer and fabricated selective emitter mc-Si solar cells. First, we compare acidic- and RIE-textured surface morphologies and reflectance. Figure 2 shows SEM images of mc-Si wafer with acid- and RIE-textured surfaces. Figures 2(a) and 2(c) are only acid-textured surface, which has smooth and bowl-like features. Figures 2(b) and 2(d) are RIE-textured surface on acid-textured wafer. This has many nanosized features in dent. And it has many deeper features than only acid-textured surface which provide very dark looks. As can be seen Figure 3, RIE-textured surface have lower reflectance than acidic textured surface in all wavelength. Especially, reflectance of RIE textured surface is less than $10 \%$ in short wavelength. This is caused by deep and dense structures, as can be seen in Figure 2.

Table 1 shows the electrical performance parameters of mc-Si solar cells fabricated with acidic- and RIE- textured surface. These cells had $50 \Omega / \square$ homogeneous emitter. As can be seen in Table 1, for the RIE-textured cell, despite the improvement in $I_{\mathrm{sc}}$, cell efficiency decrease comes from a 


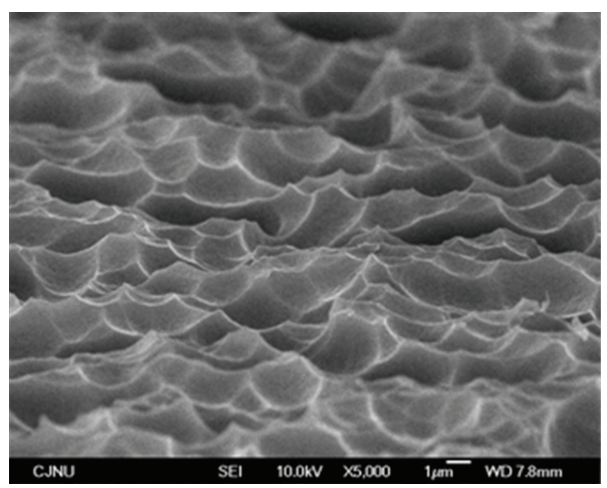

(a)

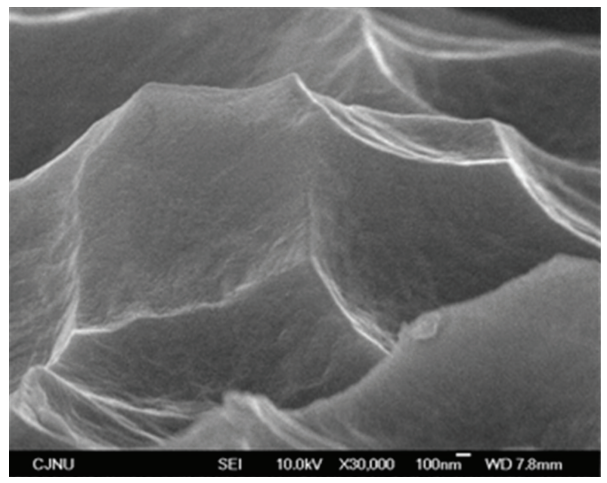

(c)

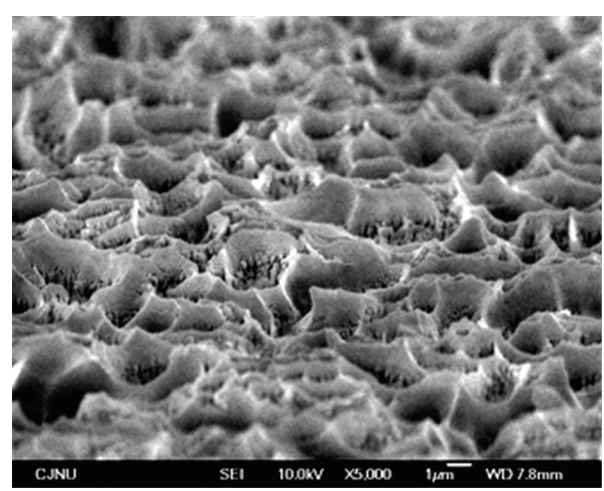

(b)

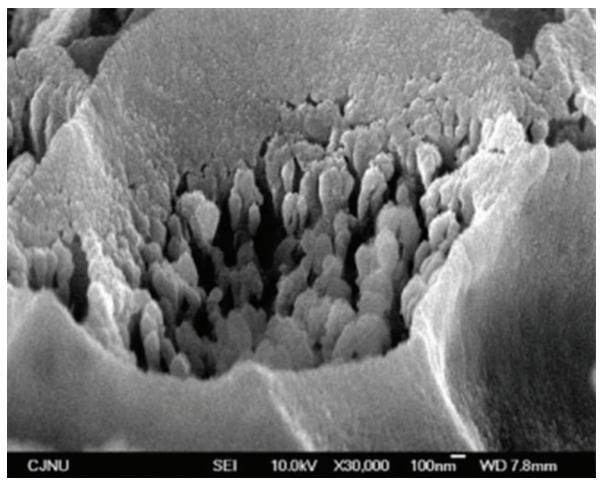

(d)

FIGURE 2: SEM images of textured surfaces: (a) acid textured surface 5000x, (b) RIE-textured surface 5000x, (c) acid textured surface 30000x, and (d) RIE-textured surface 30000x.

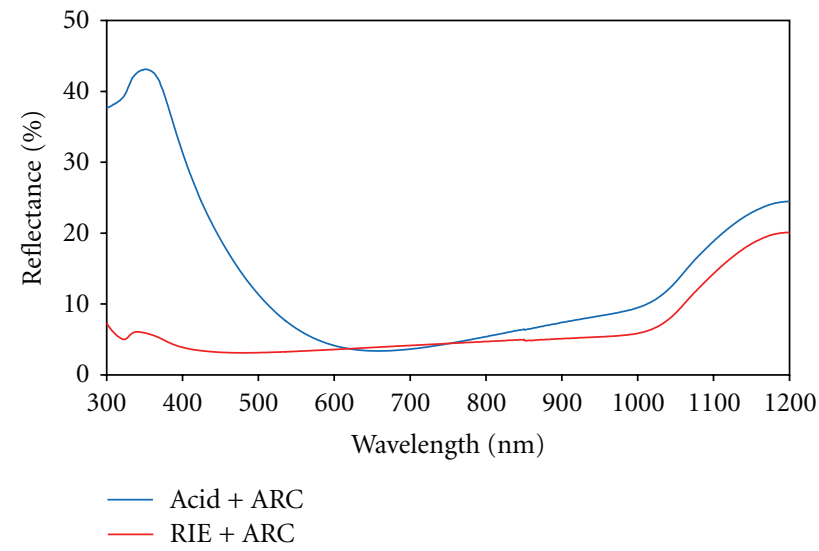

FIgURE 3: After antireflective coating, reflectance of acidic- and RIE-textured surfaces.

TABle 1: The average electrical performance of homogeneous emitter mc-Si solar cell with acidic and RIE texturing.

\begin{tabular}{lcccc}
\hline & $\begin{array}{c}V_{\mathrm{oc}} \\
(\mathrm{V})\end{array}$ & $\begin{array}{c}I_{\mathrm{sc}} \\
(\mathrm{A})\end{array}$ & $\begin{array}{c}\text { FF } \\
(\%)\end{array}$ & $\begin{array}{c}\text { Eff. } \\
(\%)\end{array}$ \\
\hline Acid texturing & 0.626 & 8.241 & 77.97 & 16.54 \\
RIE texturing & 0.619 & 8.284 & 76.88 & 16.20 \\
\hline Difference & -0.007 & +0.043 & -1.09 & -0.34 \\
\hline
\end{tabular}

drop in $V_{\mathrm{oc}}$ and FF. The most main cause for this result is surface plasma damage by RIE texturing [8]. Because problem of RIE may be that the energetic ions can introduce damage in the Si material [9], so Carriers have a large chance of recombining at the needles of the surface and will not reach the $\mathrm{p}-\mathrm{n}$ junction.

In order to remove plasma-induced damage, we studied DRE using $\mathrm{HNO}_{3} / \mathrm{HF}$ mixture with various etching times. As can be seen in Figure 4, as DRE time increases, number of nanosized features decreases and textured surface was smoother. This result means that damaged surface was gradually removed by DRE. Figure 5 shows reflectance of acidicand RIE-textured surfaces with various DRE times after antireflective coating. As DRE time increases, the reflectance 


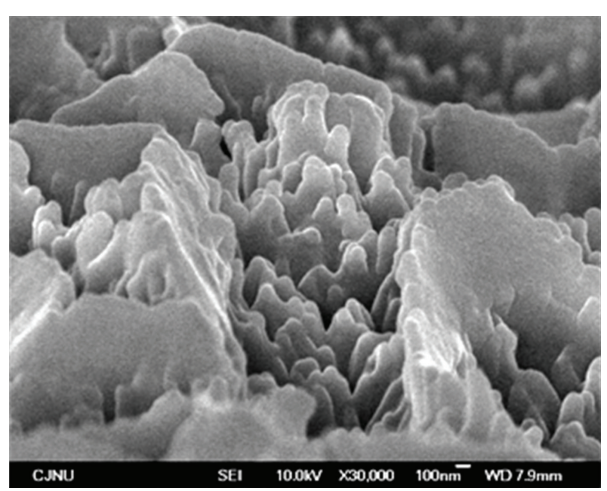

(a)

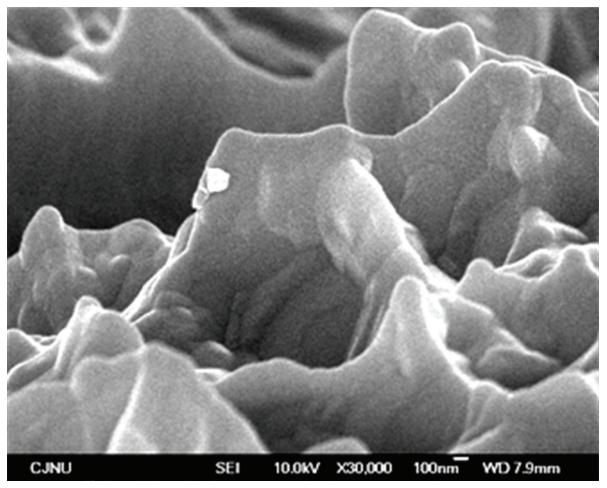

(c)

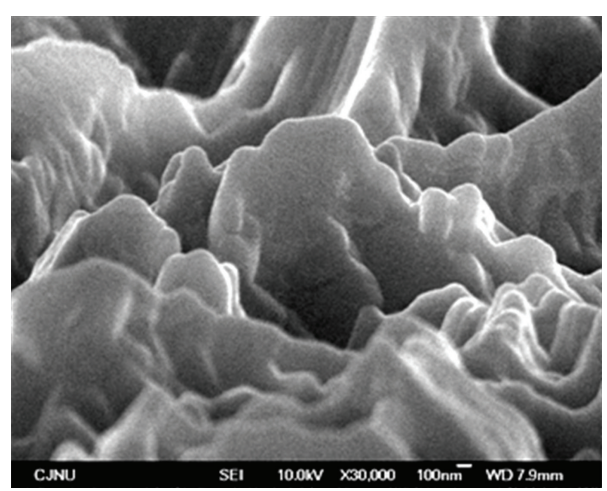

(b)

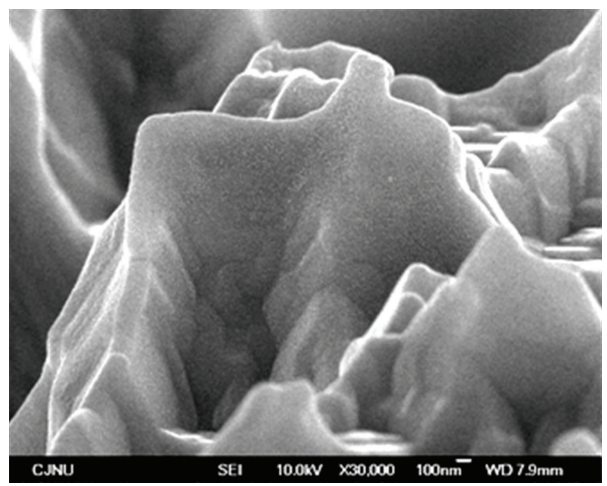

(d)

Figure 4: SEM images of RIE textured surface with various DRE times (30000x): (a) No DRE, (b) DRE 20 sec, (c) DRE 40 sec, and (d) DRE $60 \mathrm{sec}$.

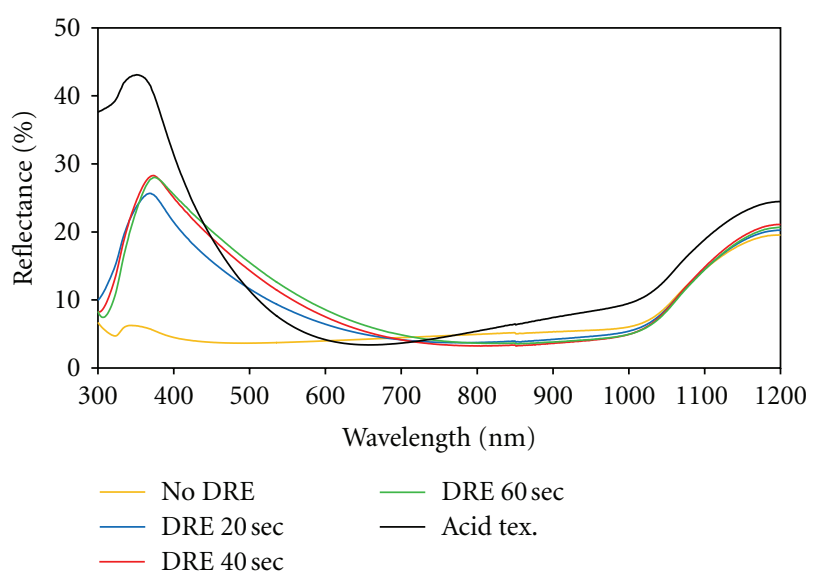

FIGURE 5: After antireflective coating, reflectance of acidic- and RIEtextured surfaces with various DRE time.

of RIE-textured surface approaches the acidic-textured surface, because the nano sized features formed during RIE process are becoming smooth by DRE. RIE-textured samples with DRE have lower reflectance than acidic-textued samples in the short wavelength region also that you can check again. So we can have a sufficiently higher $I_{\mathrm{sc}}$ than wet acidictextured samples.

Figure 6 shows electrical characteristics of RIE-textured mc-Si solar cells with various DRE times. Applying DRE, all electrical factors ( $V_{\mathrm{oc}}, I_{\mathrm{sc}}, \mathrm{FF}$, and efficiency) of mc-Si solar cell had better results than without DRE. It seems that this was caused by removing plasma-induced damage. As can be seen in Figure 6(a), as the DRE time increases, $V_{\text {oc }}$ was increased due to plasma damage etching. But, as the DRE time increases, $I_{\mathrm{sc}}$ was decreased as shown Figure $6(\mathrm{~b})$. This is consistent with results of Figures 4 and 5. As DRE time increases, because the reflectance of textured surface gradually was higher, $I_{\mathrm{sc}}$ tends to decrease slightly. And we were confirmed the highest efficiency of mc-Si solar cell in DRE condition at 20 and $30 \mathrm{sec}$ and achieved best cell efficiency applying homogeneous emitter structure.

To improve efficiency of mc-Si solar cell, we applied selective emitter structure with RIE texturing and optimized DRE condition. For selective emitter, $\mathrm{SiO}_{2}$ layer was deposited as diffusion barrier mask and patterned by etch paste for heavily diffusion. These wafers were doped in conventional tube furnace using $\mathrm{POCl}_{3}$ liquid source. The PSG and remaining $\mathrm{SiO}_{2}$ were removed with a $10 \%$ HF solution simultaneously. A shallow diffused region is created by $\mathrm{POCl}_{3}$ diffusion. After second diffusion, sheet resistance below the contact fingers was $20 \Omega / \square$ and between fingers was $80 \Omega / \square$, respectively.

Table 2 shows the result of electrical parameters of selective emitter mc-Si solar cells with acidic and RIE texturing. RIE-textured samples were applied by $20 \mathrm{sec}$ DRE condition. The value of cell efficiency is average results of 5 wafers in an experiment with neighboring wafers in ingot. We achieved above $200 \mathrm{~mA}$ absolute $I_{\mathrm{sc}}$ gain in 6 inch mc-Si solar 


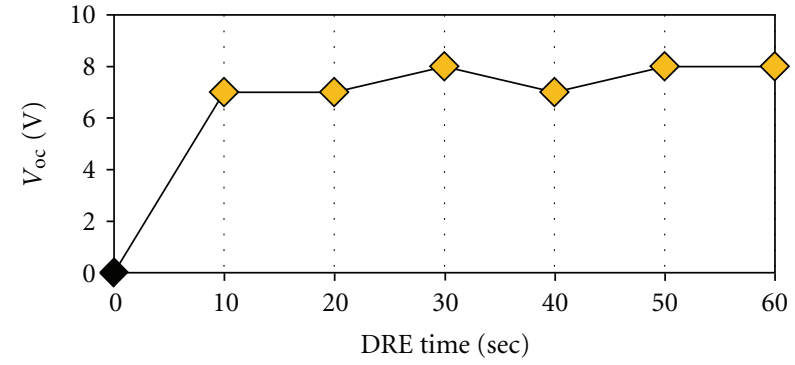

(a)

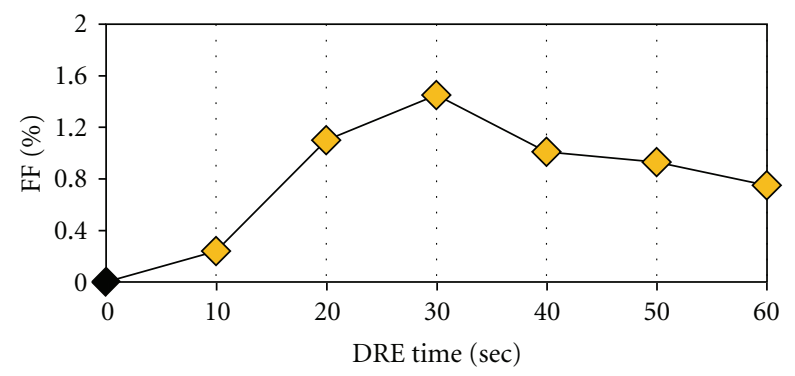

(c)

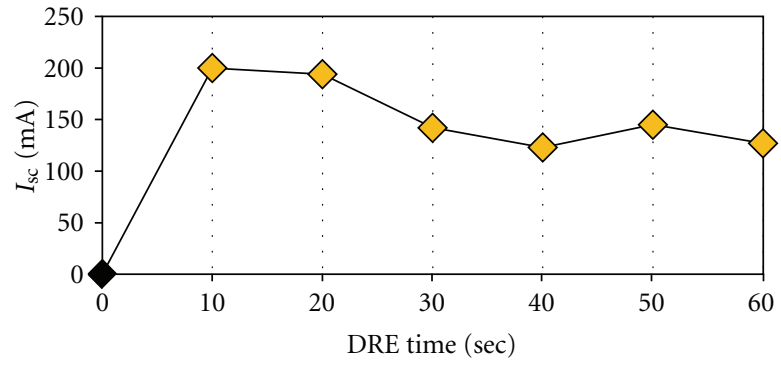

(b)

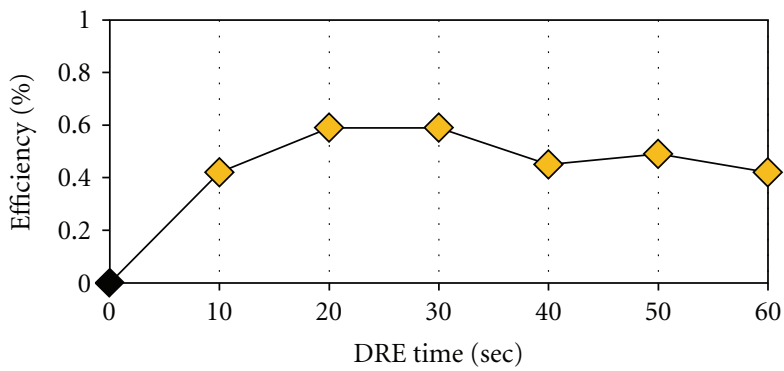

(d)

FIGURE 6: Electrical characteristics of RIE-textured mc-Si solar cells with various DRE times. (a) Open circuit voltage ( $V_{\text {oc }}$ ). (b) Short circuit current $\left(I_{\mathrm{sc}}\right)$. (c) Fill factor $(\mathrm{FF})$. (d) Conversion efficiency.

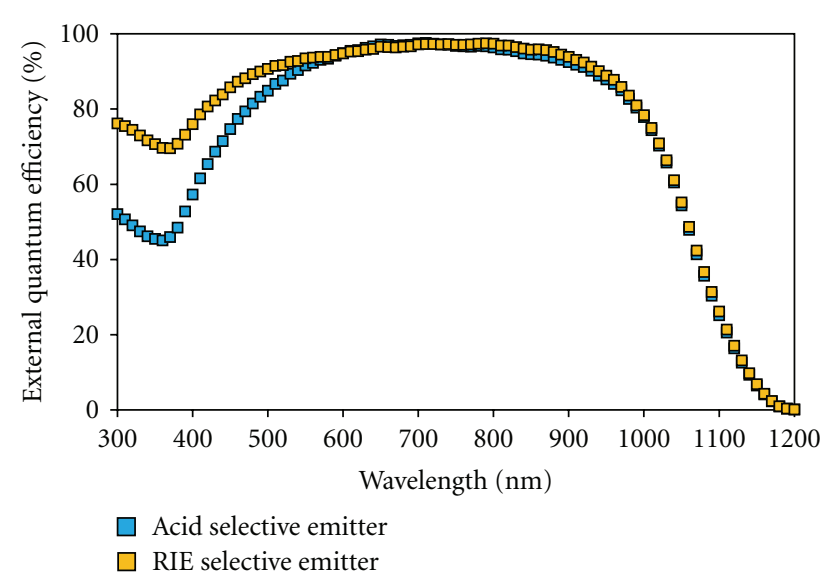

FIgURE 7: External quantum efficiency (EQE) of selective emitter mc-Si solar cells with acidic- and RIE-textured surface.

TABLE 2: The average electrical performance of selective emitter mcSi solar cell with acidic and RIE texturing.

\begin{tabular}{lcccc}
\hline & $\begin{array}{c}V_{\mathrm{oc}} \\
(\mathrm{V})\end{array}$ & $\begin{array}{c}I_{\mathrm{sc}} \\
(\mathrm{A})\end{array}$ & $\begin{array}{c}\mathrm{FF} \\
(\%)\end{array}$ & $\begin{array}{c}\text { Eff. } \\
(\%)\end{array}$ \\
\hline $\begin{array}{l}\text { Acid texturing } \\
\begin{array}{l}\text { RIE texturing } \\
(\mathrm{DRE} 20 \mathrm{sec})\end{array}\end{array}$ & 0.633 & 8.517 & 78.1 & 17.3 \\
\hline
\end{tabular}

cell by RIE- than acid-textured cells without drop of $V_{\mathrm{oc}}$ and FF. And optimized mc-Si solar cell with RIE-textured surface showed $17.6 \%$ conversion efficiency, which were made using an industrial screen printing process with selective emitter structure. And the external quantum efficiency (EQE) measurements are evaluated for the selective emitter solar cells with acidic- and RIE-textured surface, as Figure 7 shows. It is clear that the selective emitter solar cell with the RIE texturing has the improved quantum efficiency compared to acidic texturing for wavelength below $600 \mathrm{~nm}$. This results in low reflectance without plasma-induced damage.

\section{Conclusion}

RIE texturing had a deep and narrow textured surface and showed excellent low reflectance. Due to plasma-induced damage, unless the RIE-textured surfaces have the proper DRE, they have a drop in $V_{\text {oc }}$ and FF. The 20 and $30 \mathrm{sec}$ DRE times with acidic solution $\left(\mathrm{HNO}_{3}\right.$ and $\mathrm{HF}$ mixture) have the best conversion efficiency by improving the $I_{\mathrm{sc}}$ without a drop in $V_{\text {oc }}$ and FF. In order to improve efficiency of mc-Si solar cell, we applied $20 \mathrm{sec}$ DRE condition to selective emitter structure. In comparison with the acidic-textured solar cells, mc-Si solar cells with RIE texturing have above $200 \mathrm{~mA}$ absolute gain in $I_{\text {sc }}$. Optimized mc-Si solar cell with RIEtextured surface showed $17.6 \%$ conversion efficiency, which was made using an industrial screen printing process with selective emitter structure. And EQE measurements show the RIE texturing has the improved quantum efficiency compared to acidic texturing for wavelength below $600 \mathrm{~nm}$. This result in low reflectance without plasma-induced damage.

\section{Acknowledgment}

This work was supported by the New IT Project for global competitiveness strengthening of the advanced mobile devices and equipments of the Chungcheong Leading Industry Office of the Korean Ministry of Knowledge Economy. 


\section{References}

[1] H. F. W. Dekkers, F. Duerinckx, J. Szlufcik, and J. Nijs, "Silicon surface texturing by reactive ion etching," Opto-Electronics Review, vol. 8, no. 4, pp. 311-316, 2000.

[2] D. J. Thomas, P. Southworth, M. C. Flowers, and R. Greef, "An investigation of the roughening of silicon (100) surfaces in $\mathrm{Cl}_{2}$ reactive ion etching plasmas by in situ ellipsometry and quadrupole mass spectrometry," Journal of Vacuum Science \& Technology B, vol. 7, no. 6, p. 1325, 1989.

[3] J. I. Gittleman, E. K. Sichel, H. W. Lehmann, and R. Widmer, "Textured silicon: a selective absorber for solar thermal conversion," Applied Physics Letters, vol. 35, no. 10, pp. 742-744, 1979.

[4] K. Fukui, Y. Inomata, and K. Shiragawa, "Surface texturing using reactive ion etching for multicrystalline silicon solar cells," in Proceedings of the IEEE 26th Photovoltaic Specialists (PVSC '97), pp. 47-50, Anaheim, CA, USA, 1997.

[5] Y. Inomata, K. Kukui, and K. Shiragawa, "Surface texturing of large multi-crystalline silicon solar cells using reactive ion etching method," in Proceedings of the 9th International PVSEC, pp. 109-110, 1996.

[6] D. Macdonald, A. Cuevas, M. Kerr et al., "Texturing industrial multi-crystalline silicon solar cells," Solar Energy, vol. 76, no. 1-3, pp. 277-283, 2001.

[7] B. M. Damiani, R. Ludemann, D. S. Ruby, S. H. Zaidi, and A. Rohatgi, "Development of RIE-textured silicon solar cells," in Proceedings of the IEEE Conference Record of the Photovoltaic Specialists, pp. 371-374, September 2000.

[8] S. Schaefer, H. Lautenschlager, G. Emanuel et al., "Plasma etching and its effect on minority charge carrier lifetimes and crystalline silicon solar cells," in Proceedings of the 16th European Photovoltaic Solar Energy Conference and Exhibition (EU PVSEC '00), May 2000.

[9] A. R. Burgers and J. H. Bultman, "Silicon solar cells textured by reactive ion etching with natural lithography," in Proceedings of the 16th European Photovoltaic Solar Energy Conference and Exhibition (EU PVSEC '00), 2000. 


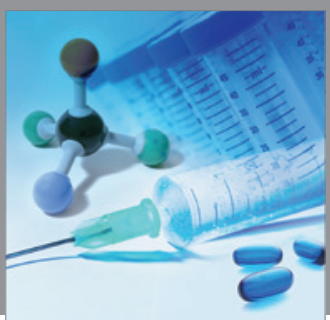

International Journal of

Medicinal Chemistry

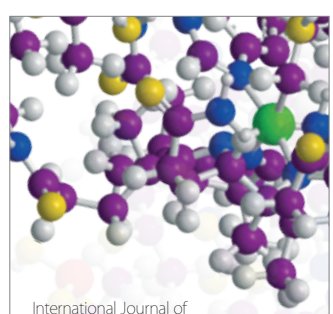

Carbohydrate Chemistry

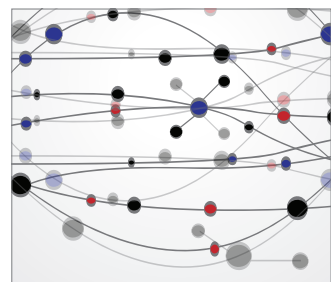

The Scientific World Journal
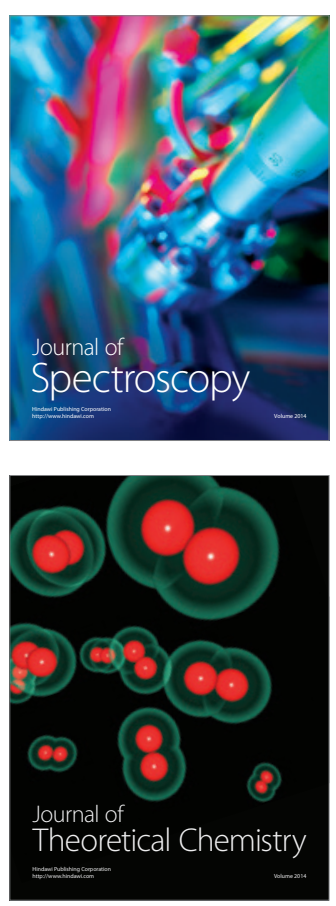
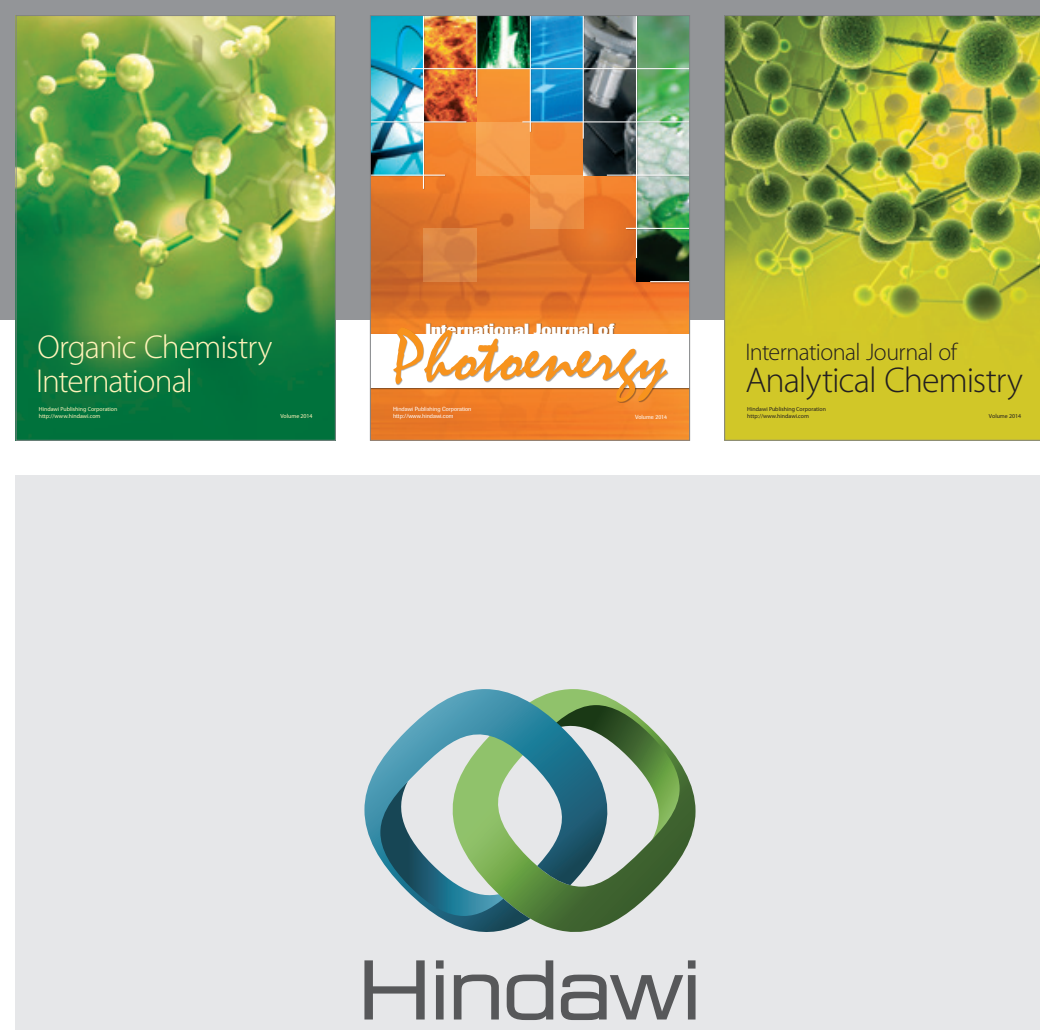

Submit your manuscripts at

http://www.hindawi.com
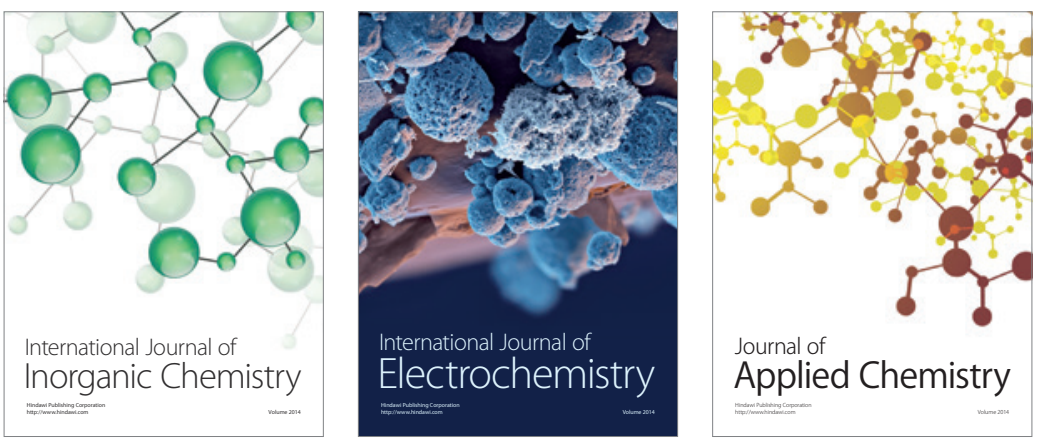

Journal of

Applied Chemistry
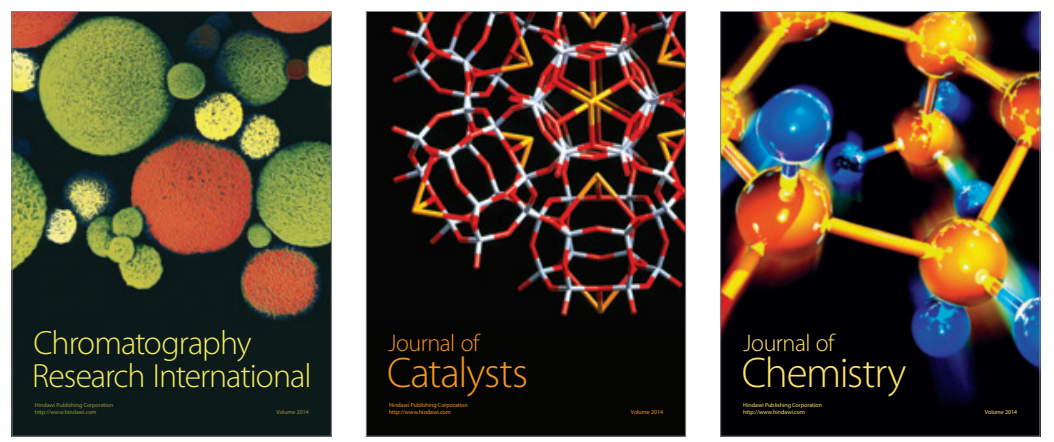
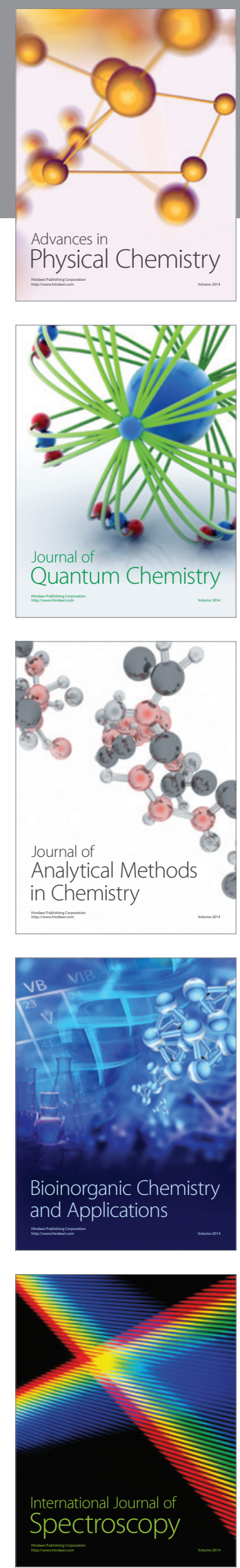